\title{
In Vitro Antimicrobial Activity of Telavancin against Methicillin-resistant Staphylococcus aureus Clinical Isolates from Japan (2006)
}

\author{
Kazuo Hatano, Kaoru Matsuzaki, Yumie Sato, Intetsu Kobayashi, Keizo Yamaguchi
}

Received: August 21, 2007 / Accepted: October 7, 2007

(C) Japan Antibiotics Research Association

\begin{abstract}
In vitro antimicrobial activity of telavancin, a rapidly bactericidal lipoglycopeptide, was evaluated against 1500 strains of MRSA recently isolated in Japan. Telavancin had potent activity, with MIC values that ranged from $0.12 \mu \mathrm{g} / \mathrm{ml}$ to $0.5 \mu \mathrm{g} / \mathrm{ml}$ and a $\mathrm{MIC}_{90}$ value of $0.5 \mu \mathrm{g} / \mathrm{ml}$. The $\mathrm{MIC}_{90} \mathrm{~s}$ of vancomycin and linezolid were $1.0 \mu \mathrm{g} / \mathrm{ml}$ and $2 \mu \mathrm{g} / \mathrm{ml}$, respectively. No vancomycin intermediate resistant or vancomycin-resistant MRSAs were detected in this surveillance study.
\end{abstract}

Keywords telavancin, S. aureus, MRSA, surveillance, vancomycin, Japan, lipoglycopeptide

The global emergence of severe infections caused by Gram-positive pathogens with resistance or reduced susceptibility to antibiotics has become a major public health concern. Importantly, among Staphylococcus aureus isolates, the frequency with which methicillin-resistant strains (MRSA) are isolated is rising [1]. In addition, MRSA strains with reduced susceptibility to vancomycin, teicoplanin and linezolid are reported with increasing frequency [2 4]. Failure of vancomycin to effectively treat serious staphylococcal infections has been reported and many experts believe that this may be due to its limited bactericidal activity $[5,6]$.

Telavancin (Fig. 1), a novel lipoglycopeptide antibiotic with a unique, multifunctional mechanism of action and rapid, concentration-dependent bactericidal activity, has completed two Phase III trials for complicated skin and skin structure infections, and is currently under evaluation for the treatment of hospital-acquired pneumonia [7]. Unlike vancomycin and teicoplanin, telavancin disrupts bacterial cell membrane integrity in addition to inhibiting peptidoglycan synthesis [8]. This dual mechanism of action may be the reason for the potent bactericidal activity observed with telavancin, which may also be a factor in limiting the emergence of resistance [8 10]. Additionally,

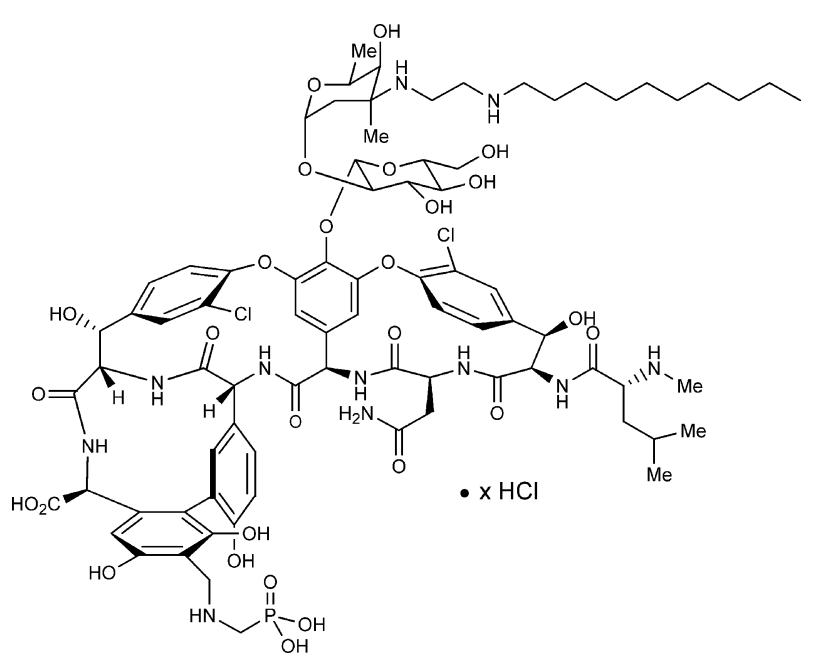

Fig. 1 Structure of telavancin.

K. Hatano (Corresponding author): Department of Infectious Diseases, Pharmacology Research Laboratories, Astellas Pharma Inc., 2-1-6, Kashima, Yodogawa-ku, Osaka, 532-8415, Japan, E-mail: kazuo.hatano@jp.astellas.com

K. Matsuzaki, Y. Sato, I. Kobayashi: Chemotherapy Division, Mitsubishi Chemical Medience Corporation, 3-30-1, Shimura, Itabashi-ku, Tokyo, 174-8555, Japan

K. Yamaguchi: Department of Infectious Diseases, Toho University School of Medicine, 5-21-16, Ohmorinishi, Ohta-ku, Tokyo, 143-0015, Japan 
this rapid bactericidal activity may provide greater efficacy, a reduction in the duration of therapy and a decrease in the relapse rate, compared with standard therapy.

In order to evaluate the potential efficacy of telavancin as an anti-MRSA agent in Japan, we determined its in vitro activity against 1,500 recent clinical isolates. The majority $(69 \%)$ of strains were isolated from the sputum, nasal cavity, accessory nasal sinus or pharynges, indicating that a large proportion of isolates were from patients with hospital-acquired pneumonia. MRSA strains were identified both by disk susceptibility testing (oxacillin inhibition zone diameter of $\leq 10 \mathrm{~mm}$ ) and growth on MRSA Screen Agar (Nippon Becton Dickinson, Tokyo, Japan) [11]. Telavancin was supplied by Theravance, Inc. (South San Francisco, California, USA). Daptomycin $\left(\right.$ Cubicin $^{\circledR}$ ) was provided by Cubist Pharmaceuticals Inc., Lexington, Massachusetts, USA) and tigecycline (Tygacil ${ }^{\mathbb{B}}$ ) by Wyeth Pharmaceuticals Inc., Philadelphia, Pennsylvania, USA). Susceptibility testing was performed according to the standards established by the Clinical and Laboratory
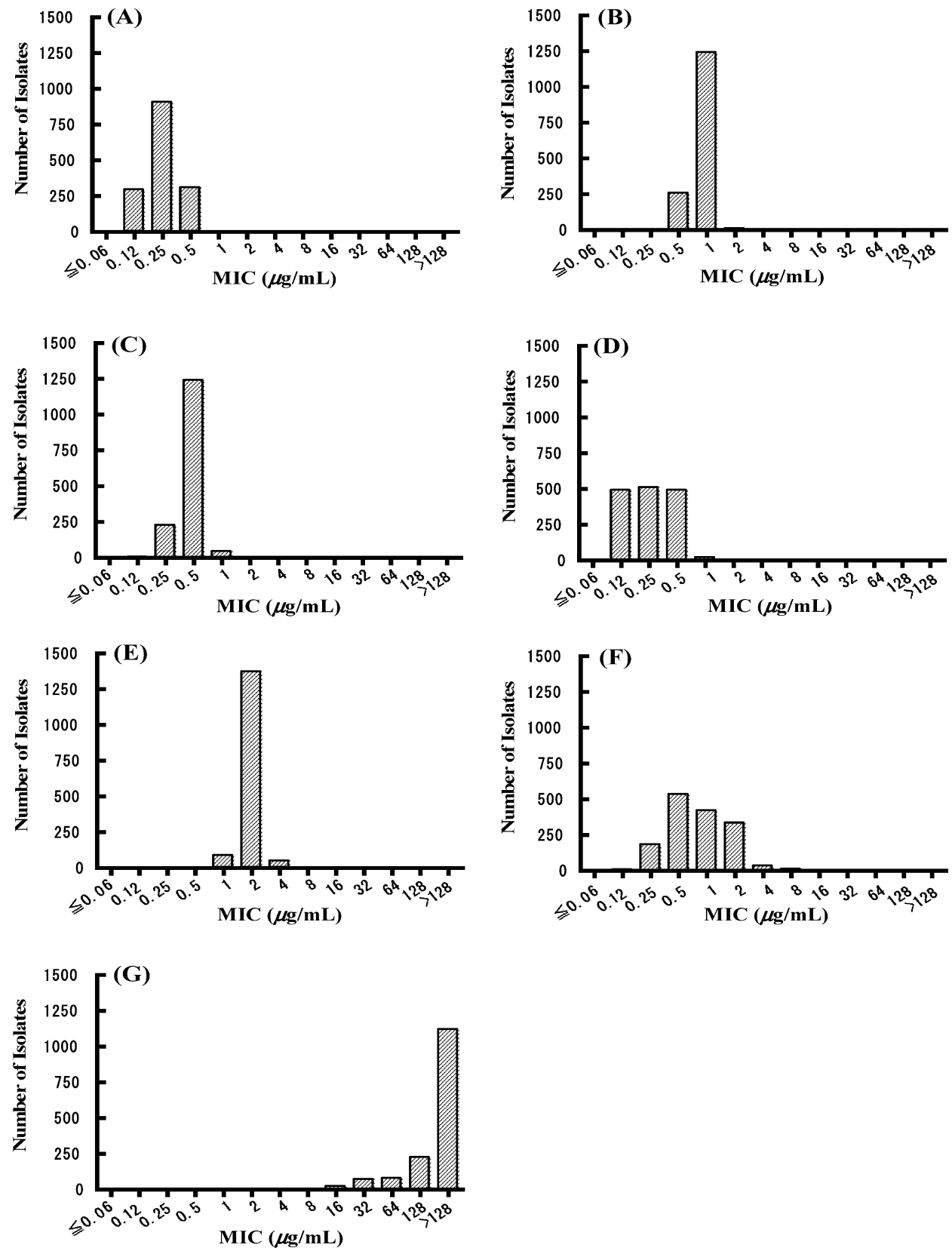

Fig. 2 MIC distributions of antibiotics tested against 1,500 MRSA clinical isolates from Japan.

(A) telavancin, (B) vancomycin, (C) daptomycin, (D) tigecycline, (E) linezolid, (F) arbekacin and (G) oxacillin. 
Table 1 Antimicrobial activities of telavancin and comparators against 1,500 MRSA clinical isolates from Japan

\begin{tabular}{lccc}
\hline \multirow{2}{*}{ Drugs } & \multicolumn{3}{c}{ MIC $(\mu \mathrm{g} / \mathrm{ml})$} \\
\cline { 2 - 4 } & Range & $50 \%$ & $90 \%$ \\
\hline Telavancin & $0.12 \sim 0.5$ & 0.25 & 0.5 \\
Vancomycin & $0.25 \sim 2$ & 1 & 1 \\
Daptomycin & $0.12 \sim 1$ & 0.5 & 0.5 \\
Tigecycline & $0.12 \sim 1$ & 0.25 & 0.5 \\
Linezolid & $1 \sim 4$ & 2 & 2 \\
Arbekacin & $0.12 \sim 8$ & 1 & 2 \\
Oxacillin & $16 \sim>128$ & $>128$ & $>128$ \\
\hline
\end{tabular}

Standards Institute (CLSI) [12] using the broth microdilution method with cation-adjusted Mueller-Hinton broth. For testing daptomycin and oxacillin, the medium was supplemented with $50 \mu \mathrm{g} / \mathrm{ml}$ of $\mathrm{Ca}^{2+}$ and $2.0 \% \mathrm{NaCl}$, respectively [11]. Eiken Chemical Co., Ltd. (Tokyo, Japan) supplied vancomycin, linezolid, arbekacin and oxacillin powders and manufactured frozen MIC panels. Collection of clinical specimens, identification of organisms and MIC determinations were carried out by Mitsubishi Chemical Medience Corporation (Tokyo, Japan). Quality control testing was performed using S. aureus ATCC 29213 and Enterococcus faecalis ATCC 29212. MIC and susceptibility were determined according to CLSI standards [11] for all antibiotics except arbekacin. For arbekacin, we used the quality control standard established by Mitsubishi Chemical Medience Corporation.

The in vitro antimicrobial activity of telavancin, compared with six other anti-MRSA agents, is summarised in Fig. 2 and Table 1. None of the strains grew on Vancomycin Screen Agar (Nippon Becton Dickinson, Tokyo, Japan), or had a MIC of $>6 \mu \mathrm{g} / \mathrm{ml}$ as assessed with the Etest (AB Biodisk, Solna, Sweden) [2], indicating that there were no vancomycin-intermediate or -resistant organisms in the collection (data not shown). Over $90 \%$ of MRSA strains in this study had high resistance to oxacillin (MIC $\geq 128 \mu \mathrm{g} / \mathrm{ml}$ ). Telavancin had potent antibacterial activity against these strains with a narrow MIC distribution $(0.12 \mu \mathrm{g} / \mathrm{ml}$ to $0.5 \mu \mathrm{g} / \mathrm{ml})$, and a $\mathrm{MIC}_{90}$ of $0.5 \mu \mathrm{g} / \mathrm{ml}$. Telavancin was two to four times more potent than vancomycin by the microdilution method and was four-fold more potent than linezolid and arbekacin. No linezolidnonsusceptible strains were identified in this surveillance study. $\mathrm{MIC}_{90} \mathrm{~s}$ for daptomycin and tigecycline, which have indication for the treatment of patients with infections such as complicated skin and skin structure infections (cSSSI) caused by microorganisms including MRSA in the USA and the EU but are not commercially available in Japan, were $0.5 \mu \mathrm{g} / \mathrm{ml}$ similar to telavancin. The results presented here are similar to those previously reported in global surveillance studies from the US (2004 2005) [13], and Europe and Israel (2005) [14].

Our surveillance study did not include vancomycin intermediate-resistant or linezolid-nonsusceptible strains. However, previous studies demonstrated that telavancin has potent activity against strains with reduced susceptibility to vancomycin [15 17], with MIC $<4 \mu \mathrm{g} / \mathrm{ml}$ even against a MRSA strain with high-level vancomycin resistance (MIC $>32 \mu \mathrm{g} / \mathrm{ml}$ ). Similarly, telavancin is not cross-resistant with linezolid [18].

In conclusion, this surveillance study showed that telavancin has potent antimicrobial activity against in vitro MRSA strains isolated in Japan, suggesting that telavancin may represent an important therapeutic option for the treatment of severe infections caused by MRSA.

\section{References}

1. Segreti J. Efficacy of current agents used in the treatment of Gram-positive infections and the consequences of resistance. Clin Microbiol Infect 11 (Suppl. 3): 29-35 (2005)

2. Tenover FC, Biddle JW, Lancaster MV. Increasing resistance to vancomycin and other glycopeptides in Staphylococcus aureus. Emerg Infect Dis 7: 327-332 (2001)

3. Appelbaum PC. The emergence of vancomycin-intermediate and vancomycin-resistant Staphylococcus aureus. Clin Microbiol Infect 12 (Suppl. 1): 16-23 (2006)

4. Potoski BA, Adams J, Clarke L, Shutt K, Linden PK, Baxter C, Pasculle AW, Capitano B, Peleg AY, Szabo D, Paterson DL. Epidemiological profile of linezolid-resistant coagulasenegative staphylococci. Clin Infect Dis 43: 165-171 (2006)

5. Moise-Broder PA, Sakoulas G, Eliopoulos GM, Schentag JJ, Forrest A, Moellering Jr RC. Accessory gene regulator group II polymorphism in methicillin-resistant Staphylococcus aureus is predictive of failure of vancomycin therapy. Clin Infect Dis 38: 1700-1705 (2004)

6. Sakoulas G, Moise-Broder PA, Schentag J, Forrest A, Moellering Jr RC, Eliopoulos GM. Relationship of MIC and bactericidal activity to efficacy of vancomycin for treatment of methicillin-resistant Staphylococcus aureus bacteremia. J Clin Microbiol 42: 2398-2402 (2004)

7. Stryjewski ME, Chu VH, O'Riordan WD, Warren BL, Dunbar LM, Young DM, Vallée M, Fowler Jr VG, Morganroth J, Barriere SL, Kitt MM, Corcy GR. Telavancin versus standard therapy for treatment of complicated skin and skin structure infections caused by Gram-positive 
bacteria: FAST 2 study. Antimicrob Agents Chemother 50: 862-867 (2006)

8. Higgins DL, Chang R, Debabov DV, Leung J, Wu T, Krause KM, Sandvik E, Hubbard JM, Kaniga K, Schmidt Jr DE, Gao Q, Cass RT, Karr DE, Benton BM, Humphrey PP. Telavancin, a multifunctional lipoglycopeptide, disrupts both cell wall synthesis and cell membrane integrity in methicillin-resistant Staphylococcus aureus. Antimicrob Agents Chemother 49: 1127-1134 (2006)

9. Pace JL, Judice JK. Telavancin (Theravance). Curr Opin Investig Drugs 6: 216-225 (2005)

10. Sahm DF, Benton BM, Jones ME, Krause KM, Thornsberry C, Draghi DC. Telavancin demonstrates a low potential for in vitro selection of resistance among key target Grampositive species. Poster C1-0681, Program and Abstracts of the 46th Interscience Conference on Antimicrobial Agents and Chemotherapy, San Francisco, September 27-30 (2006)

11. Clinical and Laboratory Standards Institute. Performance standards for antimicrobial susceptibility testing; sixteenth informational supplement. Volume 26, number 3. M100S16, Clinical and Laboratory Standards Institute (formerly NCCLS), Wayne, PA (2006)

12. Clinical and Laboratory Standards Institute. Methods for dilution antimicrobial susceptibility tests for bacteria that grow aerobically; seventh edition. M7-A7, Clinical and Laboratory Standards Institute (formerly NCCLS), Wayne, PA (2006)

13. Draghi DC, Benton BM, Jones ME, Krause KM, Thornsberry C, Sahm DF. Baseline antistaphylococcal profile of telavancin: Results of the 2004 2005 US surveillance initiative. Poster E-0715, Program and Abstracts of the 46th Interscience Conference on
Antimicrobial Agents and Chemotherapy, San Francisco, September 27-30 (2006)

14. Sahm DF, Benton BM, Krause KM, Jones ME, Thornsberry C, Draghi DC. Baseline surveillance of telavancin in vitro activity against staphylococci in Europe and Israel. Poster 193. Abstracts of Papers of 44th Annual Meeting of Infectious Diseases Society of America, Toronto, October 12-15 (2006)

15. Leuthner KD, Cheung CM, Rybak MJ. Comparative activity of the new lipoglycopeptide telavancin in the presence and absence of serum against 50 glycopeptide nonsusceptible staphylococci and three vancomycin-resistant Staphylococcus aureus. J Antimicrob Chemother 58: 338-343 (2006)

16. Tenover FC, Weigel LM, Appelbaum PC, McDougal LK, Chaitram J, McAllister S, Clark N, Killgore G, O'Hara CM, Jevitt L, Patel JB, Bozdogan B. Vancomycin-resistant Staphylococcus aureus isolate from a patient in Pennsylvania. Antimicrob Agents Chemother 48: 275-280 (2004)

17. Draghi DC, Blosser RS, Flamm RK, Sahm DF. A baseline assessment of the activity of telavancin against a collection of Gram-positive isolates, including resistant phenotypes. [Poster 1553]. Clin Microbiol Infect 11 (Suppl. 2): 505 (2005)

18. Farrell DJ, Shackcloth J, Williams L. Activity of telavancin and comparator antibiotics against clinically relevant grampositive isolates including strains with diverse mechanisms of resistance. Poster E-1746, Program and Abstracts of the 45th Interscience Conference on Antimicrobial Agents and Chemotherapy, Washington, DC, December 16-19 (2005) 